\title{
To study the health problems of workers in hospitality industry in selected units of Uttarakhand
}

\author{
NEHA MEHRA AND PROMILA SHARMA
}

Received: 10.07.2015; Revised: 24.10.2015; Accepted: 02.11.2015

$\underline{\text { See end of the paper for authors' affiliations }}$

\section{NEHA MEHRA}

Department of Family Resource

Management, College of Home

Science, G.B. Pant University of

Agriculture and Technology,

Pantnagar, U.S. NAGAR

(UTTARAKHAND) INDIA

Email : neha90.2407@gmail.com
ABSTRACT : Hospitality industry has brought tremendous growth to the global economy by providing services ranging from accommodation, sightseeing as well as other services related to the tourism industry. It not only provides employment but also plays a vital role in the economic returns of a country in the form of foreign exchange. Also the interaction with people from different cultures, thus educating people, is brought about by the hospitality industry. Hence, Hospitality industry plays a major role in the development of economies. The complexity of the sector makes it difficult to present an exhaustive view of the situation. The hotels sector employs more than 7.8 million people in the India and is characterized by high job demands and high physical workload. Non-permanent employment patterns, in particular seasonal work, are prevalent (Kristensen et al., 2005). The sector also employs a high proportion of young workers and migrant workers. This sector covers a wide range of workplaces, more than just hotels. In a study, research design is needed because it facilitates the smooth sailing of the various research operations in a systematic manner. In order to achieve the objectives of the study descriptive design was planned. Some specific health problems to the workers of different departments (front office, housekeeping, food production unit, food service unit and tours and travel unit) of hospitality industry and these health problems were arising due to their service time. When comparison was made between hotel workers in different departments it was observed that in the front office department maximum 56.7 per cent workers respond that they were quite often suffering with the visual fatigue problem due to service while in the department of housekeeping they said that they quite often suffered with the slips, trips/falls problem. On the other hand, it was found that highly 68.9 per cent workers who were working in the food production department reported that they were almost never suffering with ischemic heart disease and 62.9 per cent food service department workers' said that they almost always suffered with manual handling problem. At the end of the comparison, tours and travel department workers' felt that 57.9 per cent were quite often suffering with the respiratory infection health problems due to service.

KEY WORDS: Hospitality units, Front office workers, Housekeepers, Food production unit workers, Food service unit workers, Tours and travels unit workers, Health problems

- HOW TO CITE THIS PAPER : Mehra, Neha and Sharma, Promila (2015). To study the health problems of workers in hospitality industry in selected units of Uttarakhand. Asian J. Home Sci., 10 (2) : 353-359. 